\section{Discussion}

Heartsink patients are a great source of stress to doctors, and the feeling of heartsink may be the only common thread joining a disparate group of difficult patients. Because the problem has never been quantified in practices there is often a feeling that it is bigger than it really is. In this study getting more information about the patient and family seemed to make them less heartsink. With a greater understanding of the patient, it is likely that the doctor was relieved of any clinical insecurity and became more positive about the patient. These patients grated with the practice; however, it is likely that the doctors' negative feelings were transmitted to the staff or to each other as in Stockwell's study of nurses and unpopular patients. ${ }^{6}$

The meetings were structured to search for reasons for the patients' discontent, which now sounds like missing the point. None the less searching for such reasons often produced dilemmas which meant the discussion group had achieved a degree of sharing and support that might not have happened if it had been the declared purpose of the group. The group always formulated a management plan. This again might seem inappropriate, but it changed an often helpless doctorpatient relationship into a more positive state of affairs. Undoubtedly, the negative feelings such patients aroused in us made us feel "unprofessional," causing puzzlement, frustration, and disappointment. Our scientific and medical training, hurried working conditions, and unsupported professional needs concentrates our preference for standardised behaviour.

Heartsink patients cause much clinical insecurity. It is reassuring to know that the heartsink patients in this group do not seem to have suffered from missed diagnoses, but like the results of other studies have shown many had chronic medical and psychological problems. $^{3578}$ There is of course the great danger that such illness may be poorly managed when the doctor would really prefer not to see the patient.

The nature of this work can be likened to what Marinker has called a journey into the interior of general practice. ${ }^{9}$ It is a lonely journey that many doctors make regularly and is one of the most complex problems we face. The features are unique to general practice. In the past general practice has permitted and benefited from outside views of its problems; we need help with this problem because we are part of it and thus find understanding it difficult.

Many clinicians and non-clinicians have helped in the writing of this paper. Particular thanks go to my colleagues at Llanedeyrn Health Centre, Cardiff and my colleagues in the Department of General Practice, Nottingham. Professor John Horder provided valuable critical comment.

1 Ellis CG. Making dysphoria a happy experience. BrMed $\mathcal{~ 1 9 8 6 ; 2 9 8 : 3 1 7 - 8 . ~}$ 2 Groves JE. Taking care of the hateful patient. $N$ Engl f Med 1978;298:883-7. 3 Westhead JN. Frequent attenders in general practice: medical, psychological and social characteristics. $\mathcal{J} R$ Coll Gen Pract 1985;35:337-40.

4 Ries RK, Bokan JA, Katon WJ, Kleinman A. The medical care abuser: differential diagnosis and management. F Fam Pract 1981;13:257-65.

differential diagnosis and management. F Fam Pract 1981;13:257-65.
5 Courtenay MJF, Carwen MP, Dave D, Robinson J, Stern MJ. Frequent attendance in a family practice. $\mathcal{F} R$ Coll Gen Pract 1974;24:251-61.

attendance in a family practice. $\mathcal{F}$ R Coll Gen Pract 1974;24:251-61.
Stockwell F. The unpopular patient. London: Croom Helm, 1984.

6 Stockwell $F$. The unpopular patient. London: Croom Helm, 1984 .
7 Wamosher $Z$. The returning patient. A survey of patients with high attendance Wamosher $Z$. The returning patient. A survey of patients with high a
rates. Fournal of the College of General Practitioners 1966;11:166-73.

8 Semmence A. Chronic users in a general practice. A preliminary study. $7 \mathrm{R}$ Coll Gen Pract 1969;17:304-10.

9 Marinker $M$. Journey to the interior: the search for academic general practice. fR Coll Gen Pract 1987;37:385-7.

(Accepted 8 June 1988)
London N10

T J Gerrard, MRCGP, general practitioner principal

\section{London N6 4QA}

J D Riddell, MRCGP, general practitioner principal

Correspondence and requests for reprints to: Dr T J Gerrard, 1 Dukes Avenue, London N10 2PS

\title{
Difficult patients: black holes and secrets
}

\author{
T J Gerrard, J D Riddell
}

The despair, anger, and frustration that we feel with certain patients is part of our everyday lives; we are all familiar with that feeling which overwhelms us when we see Mr or Ms X's name in the visit book. We have been taught that these feelings often originate in the patient, and we try to use this insight to help them.

These patients usually attend frequently; it is not this that causes difficulty but the style and the content of the consultation. They often seek out a particular partner in the practice and then stay with him or her, and this special relationship can cause intense rivalry and resentment between partners. One doctor's list of difficult patients is not the same as another's, and this must reflect the needs and personalities of different doctors. We have found that a long case meeting to discuss these patients and the feelings they produce can be invaluable, but we also believe that further analysis of these particular patients as outlined in this paper can be helpful.

We looked at the first 25 names that came to mind and found that they all had one or more of $10 \mathrm{key}$ characteristics as described below. We have given examples based on real cases and suggested ways to understand and unlock patient and doctor. (Throughout the doctor is assumed to be male for the purposes of simplicity.)

\section{The ten categories}

BLACK HOLES

These patients demand help persistently but are expert at blocking it. There is no movement in their situation and they induce a feeling of helplessness in the carer. They are well versed in adopting an oppositional stance to whatever approach is made by the doctor. Younger inexperienced doctors feel especially vulnerable to their endlessly suffering, yet resisting, stance.

$\operatorname{Mrs} A$ is 79 years old and in her own words hasn't felt well for 25 years; her main complaints are exhaustion and weakness. She forms attachments, particularly to trainees in the practice, and is triumphant when their energy and interest do not reveal any underlying disease. Her four inch records show the extent of her success as a black hole.

The counter-The only approach likely to bring any relief is a paradoxical manoeuvre such as is used in family therapy_for example "There isn't a doctor in the world clever enough to help you" (response: "Well doctor, at least you tried"), or "I can't understand how you cope with what you have to and still want to go on living" (response: "I'll just go on trying a little bit longer").

\section{FAMILY COMPLEXITY}

It is impossible to disentangle these patients' problems from those of their family, and often the patient who presents is in reality the least sick member. They often have dysfunctional consultations as a result.

$M r$ and $M r s$ are both elderly and have spent a lifetime disliking each other. They compete for the 
doctor's attention and separately claim to be more worried about the other. Their family perpetuate this and obscure the truth still further.

The counter is to insist on seeing the whole family together. This exposes the family dynamics and can release "the patient."

\section{PUNITIVE BEHAVIOUR}

These patients make the doctor pay for real and imagined grievances and are most animated when they are successful. This punitive behaviour may either reflect a stage in a process, such as bereavement or serious illness, or may be an integral part of their personality.

$\mathrm{MrC}$ takes a close interest in medical matters and uses his knowledge to corner the doctor. His hope is to punish the doctor and prove him wrong.

The counter is to admit to ourselves that we do not know everything, nor is it reasonable that we should. This may free the doctor from being threatened by the patient. Sometimes it may also be appropriate to confront the patient in order to expose his punitive approach.

\section{PERSONAL LINKS TO THE DOCTOR'S CHARACTER}

The doctor shares the patient's hopes and fears and may foster a dependent relationship. They suffer together, and this obscures the decisions that have to be taken as well as deskilling the doctor.

Mrs $D$, a bright vivacious woman, is left trapped in her unsupportive family by a sudden stroke. She is in continuous pain and becomes very depressed. She threatens to commit suicide. The doctor can understand why.

The counter-The doctor must first recognise that he is no longer as detached as he would expect. He should then share this with his colleagues; this can allow the doctor to see why he has become tangled with the patient. This insight can then free him to act more appropriately.

\section{DIFFERENCES IN CULTURE AND BELIEF}

The patient's and doctor's frames of reference are different and there is no shared language. Both can at times feel antagonistic towards the other's beliefs, and this can entrench the positions of either the patient or the doctor.

$M r$ and $M r s E$ have a child with severe asthma. They persist in treating her with homoeopathic remedies without any improvement, and only in extremis will they reluctantly accept conventional treatment.

The counter is for the doctor to re-examine his own prejudices and to be open about his position, which may allow the patient to do the same. This may be the first step towards the patient trusting the doctor.

\section{DISADVANTAGE, POVERTY, AND DEPRIVATION}

Since disadvantage, poverty, and deprivation increase the incidence of certain types of ill health it follows that the doctor can often act only through changing social and environmental factors. The difficulty in bringing about such change and the deprivation itself can further impoverish the relationship.

Family $F$ lives in a cold damp flat; they have never had hot water or heating in bringing up their five children and caring for the grandparents. They share bedrooms and have coped with childhood death, mental illness, rape, and abuse from their landlord without expectation.

The counter is to understand that the doctor can often do nothing to improve their situation. What help can be offered is often painstakingly slow.

\section{MEDICAL COMPLEXITY}

It is easy to feel deskilled by a patient suffering from one or more complicated or obscure illnesses. Sometimes the patient knows more about these than the doctor.

Miss $G$ was born with an extremely rare condition affecting her growth. She has been to five eminent specialists here and abroad. Her parents have researched widely into the medical literature and have their own clear ideas about her care.

The counter-The key to these situations is to identify when the general practitioner, the patient, and hospital are working in opposition. Each of the three has complementary skills and often it is appropriate that the patient is the expert. Rather than feeling threatened by ignorance we should remember we are experts at facilitation and conciliation. As family doctors our overall perspective is different from that of the hospital doctor, and this can be helpful for the patient.

\section{MEDICAL CONNECTIONS}

We all have nurses, doctors, and their families as patients and are aware of wanting to provide special care while being fearful of making mistakes. This overcompensation unbalances the relationship from the beginning and clouds the issues for both doctor and patient.

$M r$ and $M r s ~ H$ are successful and wealthy doctors who consult frequently. They state that the care they receive is the very best, which sets off a spiral of expectations that is doomed to end in failure.

The counter is an early statement which defines who is the patient and who is the doctor. This pre-empts the emergence of a special relationship based on mutual flattery and membership of the medical profession.

\section{WICKED, MANIPULATIVE, AND PLAYING GAMES}

Often the sweetest and most flattering patients play the wickedest games. This may turn colleagues against each other and cause disruption. Their aim is to exercise power to bolster their feelings of impotence.

Mrs $I$ used to work at the surgery and delights in hearing practice problems since she left. She is overtly charming and friendly in consultation, yet elsewhere is highly critical and undermining.

The counter-Colleagues must pool information about such patients so that the real position is exposed. This may result in a confrontation with the patient.

\section{SECRETS}

There is an uneasy unspoken feeling about many of our most difficult patients. We sense a missing link which is always avoided in consultation. This family or personal secret is the core of their life and their problems.

$M r s \mathcal{F}$ has had 50 years of illness. The medical profession has repeatedly admitted her to hospital and enthusiastically subjected her to investigations and operations. Recently she has revealed that when she was a child she was repeatedly raped over many years by her stepfather. She has sworn the doctor to absolute secrecy and refuses to reveal her secret to her husband.

The counter-With time and developing trust patients may reveal their secret. Sharing the horror with them can help exorcise their guilt. The secret can then often be shared more widely and in this way become integrated into their lives; the skeleton is therefore replaced in time by real support. The extent to which the secret permeates their life is a measure of the horror and shame that they feel. Like an unmourned death, it keeps the distress alive, and this allows no examination of the reality of their guilt and responsibility. The idea that family and friends would be soiled by knowing the 
secret is a fantasy; this fantasy is protected and acts as a private comfort and explanation for a failure to develop their lives further. The doctor is often told because of the promise of confidentiality which maintains the secret; it is often, however, the first step to sharing the secret more widely so that the patient can then move on to recover.

\section{Conclusion}

This analysis was prepared in the course of thinking about difficult patients, and many of them inevitably belonged to more than one category. We were surprised by some of the patients who were high scorers, especially by the large number of black holes and those with family complexities and secrets. We believe that time spent with "black holes" would often be better spent with other patients.

Family interviews are increasingly part of our everyday practice. In nearly all our families there seemed to be a secret that had lain untold for many years. We would almost go so far as to suggest that in those patients who do not quite make sense, in whom the story and persona don't quite fit, there is a secret.

We are encouraged to find that many of our difficult patients now seem less troubling. We think this has come about partly because we have re-examined our own management based on these categorisations and partly because the patients have benefited from this new approach. Some have been confronted while others have sensed a change: Family B have been seen together with encouraging results; Mrs $\mathrm{J}$ is talking more openly about her secret.

To examine those patients we carry around with us is a way for general practitioners to make sense of them. At the very least this analysis is a comfort for the doctor. At best patients may find they do not need to be ill.

\section{Correction}

Uptake of immunisation in district health authorities in England

In the introduction of their article (25 June, p 1775) Professo Brian Jarman and colleagues cited the proportion of routin immunisations performed by general practitioners in Northumberland as $27 \%$. In fact Northumberland District Health Authority estimates that in $198780 \%$ of preschool immunisation were performed by general practitioners.

\section{ONE HUNDRED YEARS AGO}

Sir John Millais has contributed to a recent number of the Magazine of Art an article entitled "Thoughts on our Art of to-day," which presents many points of interest. The author is a thorough optimist, and believes that ability and talent are as abundant as ever, and that art has not degenerated but that the demands of art have changed and expanded with the advance of time. It may be pointed out that the intelligence and taste of the public have changed also; a considerable amount of knowledge of the physiology of expression is diffused among us, so that the average man is much more a student of human form and action than in former times. All educated people look at, and, to some extent, admire and learn from the bes productions of art. What is it that the artist tries to teach in his figure paintings? We do not here refer to Sir John Millais's works, or those of any particular artist. The author complains of the art critic that "he makes no allowances for the charm of mutilation or the fascination of decay." $\mathrm{He}$ does not say that such cause of admiration is to be defended, but that it is popular; he says, on the other hand, that "the great painters all painted in bright colours, such as it is the fashion nowadays for men to decry as crude and vulgar." Having referred to the prevalent taste which leads many men never to have green in a picture, and who will even stipulate when giving a commission that the canvas shall contain none of it, he says, "But God Almighty has given us green, and you may depend upon it it is a fine colour." In this ejaculation, in contrast to admiration of the professional art critic for "the charm of mutilation, or the fascination of decay," we see an indication of the desire of the physiologist to find expression of the artist's idea of the perfect man in noble attitude and action, such as may elevate and instruct; the beholder may then say, "Here is what a man may be and do." To express on canvas, as the writer may do in word-painting, the higher being and lives of men, is worthy of the artist and his noble profession. Sir John appeals to Nature's work as a defence for introducing a colour which happens to be out of fashion with a certain set of critics; we would add like remarks as to modes of expression in figures which are in vogue among some painters. Should we be called upon to admire the semblance and attitudes of maudlin weakness and hysteria sometimes represented in females as forms of beauty? or complexions showing the sickliness of anaemia or gross asymmetry of the body, and infants far gone in marasmus; figures with most of the mobile features and members hidden or absent from the individual, figures with forms of beauty but destitute of the expression of brain action? We are interested in the artist's work, not only because it is beautiful, but because it may teach us something of the more perfect types of the human figure in rest and in action, and may put before the public that which they tend unconsciously to imitate in gait and bearing. A good figure is a good teaching; children may be impressed and instructed by the picture of a noble man or woman, as well as by the story of noble deeds. We are glad to think with Sir John Millais that the present generation of young men is no more retrocedent in power in art than in science and literature; it would be sad if it were otherwise.

We may learn many things from art besides the admiration of beauty; workers in the profession of art inherit a mass of knowledge as to the types of human form and action of great value to the physician, who studies human perfections as well as its weaknesses. The artist's work is in many ways the reverse of that of the scientist. It has been said, "A work of art can only be said to be finished when all traces of the means whereby its completion has been arrived at have entirely disappeared." The scientific worker desires not only to arrive at a satisfactory end of his work, but also to demonstrate, if possible by specimens, the steps of the inquiry by which his conclusions were reached; the amateur artist is sometimes satisfied with producing an affect pleasing to the eye, without analysing the means he uses. This remark may be applied to figure compositions-an effect in figure painting may be beautiful without being admirable; it may not represent a healthful man or woman, though put forward as the artist's representation of youthful beauty. Just so in social life; attitudes are sometimes adopted as being attractive which we commonly see as indications of weakness, nervousness, or hysteria. We would urge upon the art student the study of the physiology of expression; it is a delightful study, and one that can be carried on in any place where there is man, woman, or child, as is well illustrated in the works of Leonardo da Vinci and Sir Charles Bell, all mankind are his subjects for a study; fine mobile expression in face and limbs may be seen in poorly cut bodies, and in the study of defects he will learn to avoid them.

All students must advance their education with the advance of the times; the art student has given more attention to anatomy than to physiology as a science, yet his work is eminently concerned with the physiology of brain expression. Sir John Millais, speaking of young men of talent, says, "We must not forget that only by insistence upon their individuality of conception and expression can they hope to advance to the first rank." We submit that to conceive a figure well, it is advisable to be able to describe action and attitudes of the human body, and to know something of the causes, as well as the circumstances, which produce them. Several artists have said that it is so difficult to paint hands, and that this explains why they are so often omitted in figure sketches, yet it is well known that after the face these members are the most expressive of brain condition. Are hands generally represented free to express the mental state, or occupied in holding an object, in resting, or hidden and got rid of where they cannot be seen? Does not this arise from want of study of expression in the human hand? Our author gives his personal experience thus: "Sometimes as I paint I may find my work becoming laborious, but as soon as I detect any evidence of that labour, I paint the whole thing out without more ado." If fatigue incapacitates an artist's hand for good work, this may give the clue to the meaning of the signs of weakness too often seen in figures drawn on canvas with heads and backs bent, and hands which indicate weariness in the living model, only too truly imitated when the draughtsman is incapable of seeing the signs of fatigue in the subject of his study. Further study of the physiology of expression might enable the young artist better to conceive his figures, and to model them to express the ideas he wishes to convey. (British Medical Fournal 1888;ii:132) 